\title{
Developmental venous anomaly: a rare cause of cerebellar ataxia
}

\section{Ashley Griswold}

Nova Southeastern University, Davie, Florida, USA

\section{Correspondence to} Ashley Griswold, ag1749@nova.edu

Accepted 8 March 2016
CrossMark

To cite: Griswold A. BMJ Case Rep Published online: [please include Day Month Year] doi:10.1136/bcr-2016215004

\section{DESCRIPTION}

The most common causes of acute cerebellar ataxia are vascular disorders resulting in cerebellar ischaemia or haemorrhage. Most cerebellar haemorrhages are midline and therefore present with gait ataxia, truncal ataxia, dysmetria of lower extremities, saccadic intrusions and vertigo. Symptoms for cerebellar hemisphere lesions include dysdiadochokinesis, dysmetria of upper extremities, limb ataxia, intention tremor and scanning speech. Chronic progressive ataxias are most commonly degenerative and

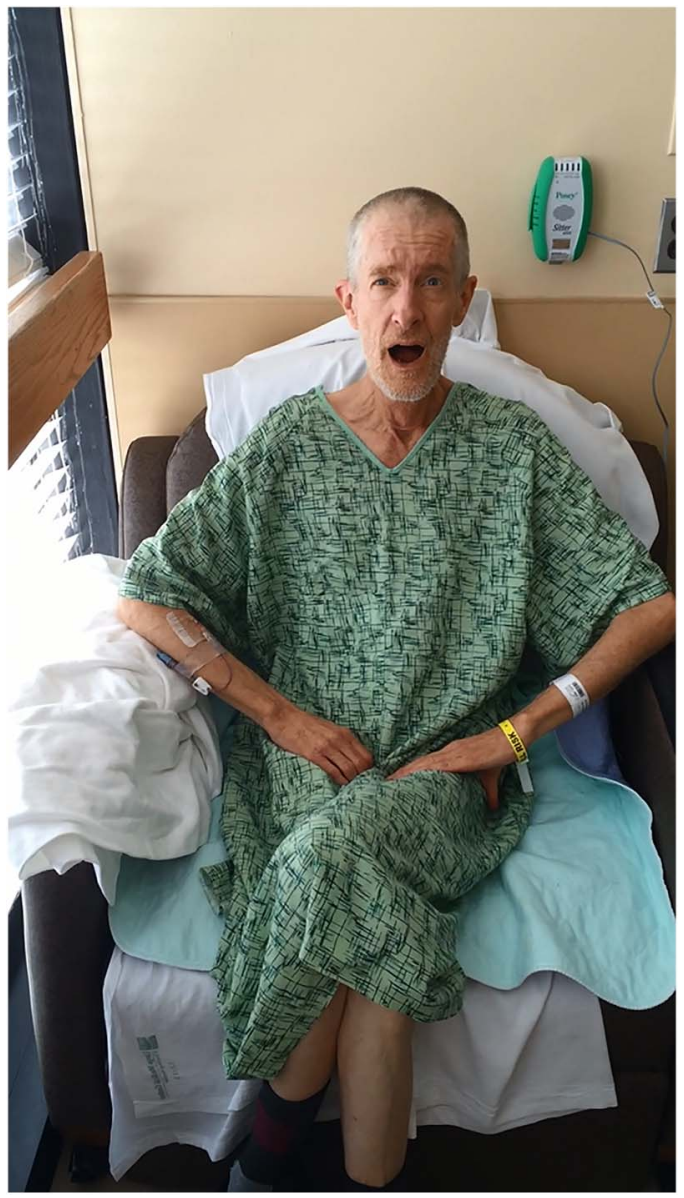

Video 1 Ataxic dysarthria with normal mentation. frequently hereditary in origin; they account for half the cases of adult onset ataxia. ${ }^{1}$

Developmental venous anomalies are commonly encountered congenital anatomical variations of the cerebral vasculature-a malformation of medullary veins separated by normal brain parenchyma. ${ }^{2}$ They are considered benign lesions that may uncommonly present symptomatically. ${ }^{3}$

We present a case of a 13-year history of acute onset, progressively worsening cerebellar ataxia with a developmental venous anomaly presenting

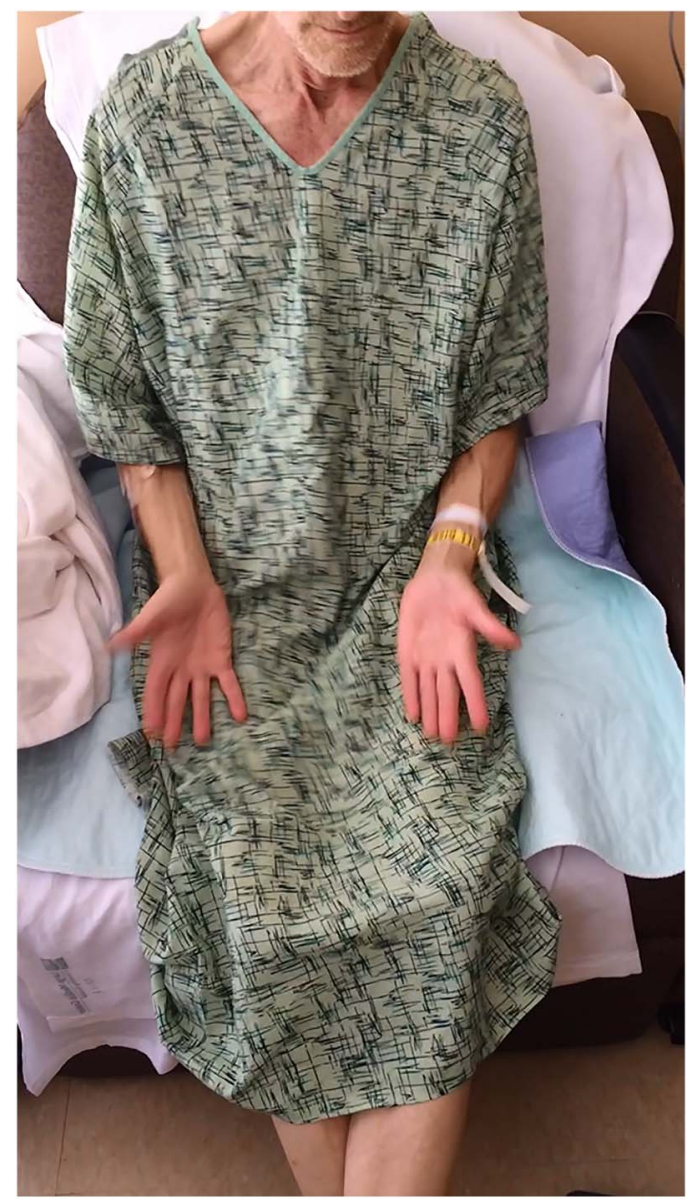

Video 2 Dysdiadochokinesis. 


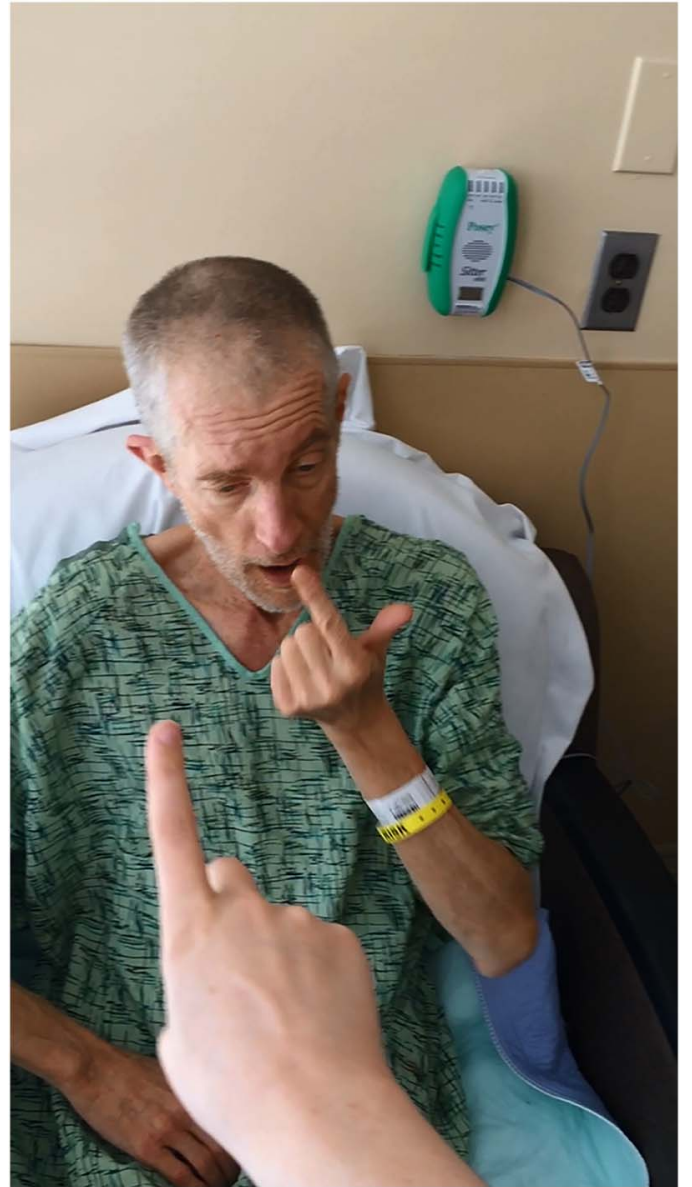

Video 3 Dysmetria of upper extremities.

in a 62-year-old man. He was admitted for cerebellar ataxia. He reported a medical history of acute onset of cerebellar ataxia in 2003 as well as a 45-pack year tobacco use disorder. In the past month, the patient reported repeated falls as well as a low

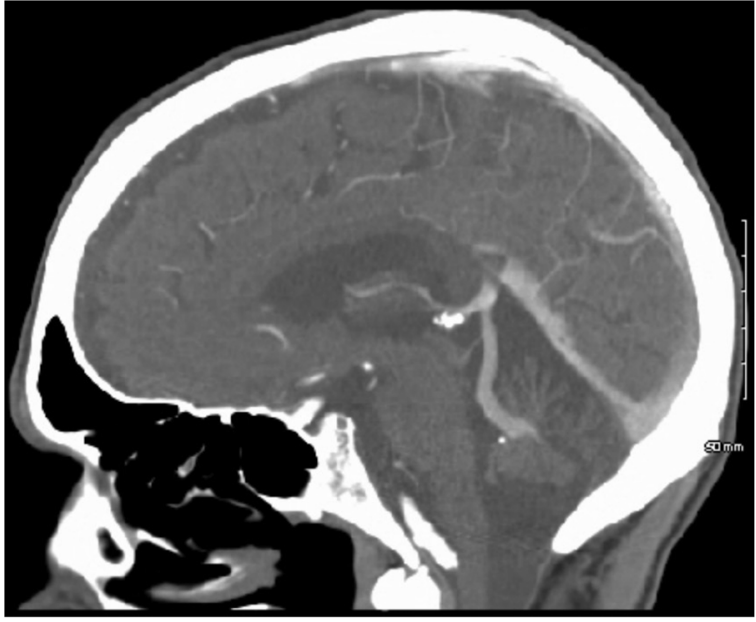

Figure 2 Cerebellar developmental venous anomaly revealed on CT angiography of the brain, sagittal view.

velocity, frontal impact motor vehicle collision requiring extrication, 1 week prior to presenting to the emergency room. $\mathrm{He}$ reported worsening dysphagia and progressive weight loss. $\mathrm{He}$ denied any recent illness or malaise.

On physical examination, he appeared cachectic (body mass index $16.4 \mathrm{~kg} / \mathrm{m}^{2}$ ) alert, oriented and in no acute distress (video 1). $\mathrm{He}$ presented with an intention tremor, dysdiadochokinesis (video 2), dysmetria of the upper extremity (video 3), dysphagia, broad-based gait and ataxic dysarthria (video 1).

During his admission, CT angiography of the brain (figures 1-3) and MRI of the brain (figures 4-6) were performed, revealing a developmental venous anomaly in the cerebellar vermis, cerebral and cerebellar atrophy and chronic deep white matter ischaemic changes. The combined cerebellar atrophy and developmental venous anomaly is believed to have resulted in the cerebellar ataxia. Neoplastic and paraneoplastic disease was not excluded.

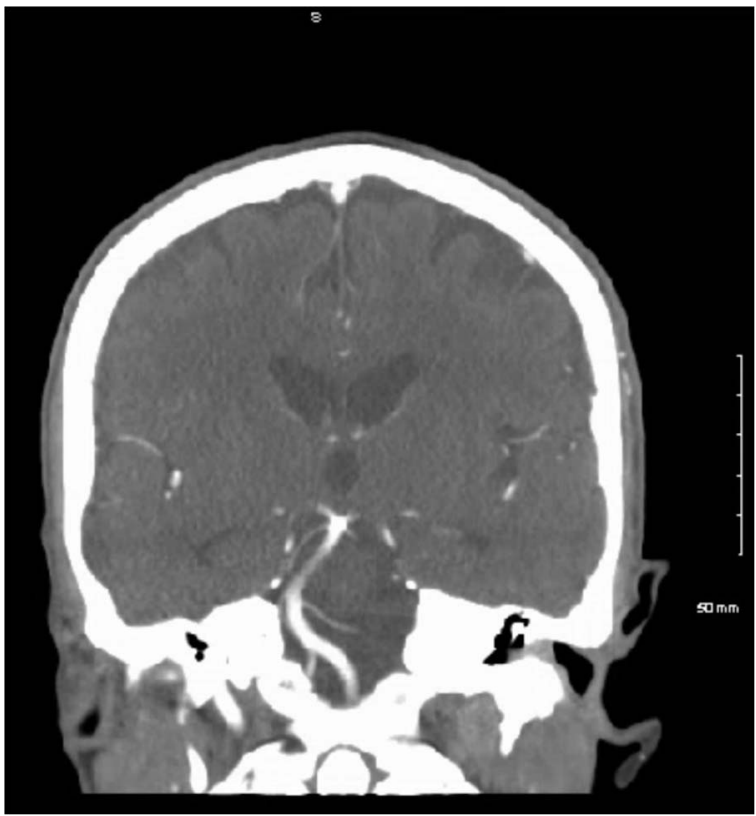

Figure 3 Cerebellar developmental venous anomaly revealed on CT angiography of the brain, coronal view.
Figure 1 Cerebellar developmental venous anomaly revealed on CT angiography of the brain, axial view. 


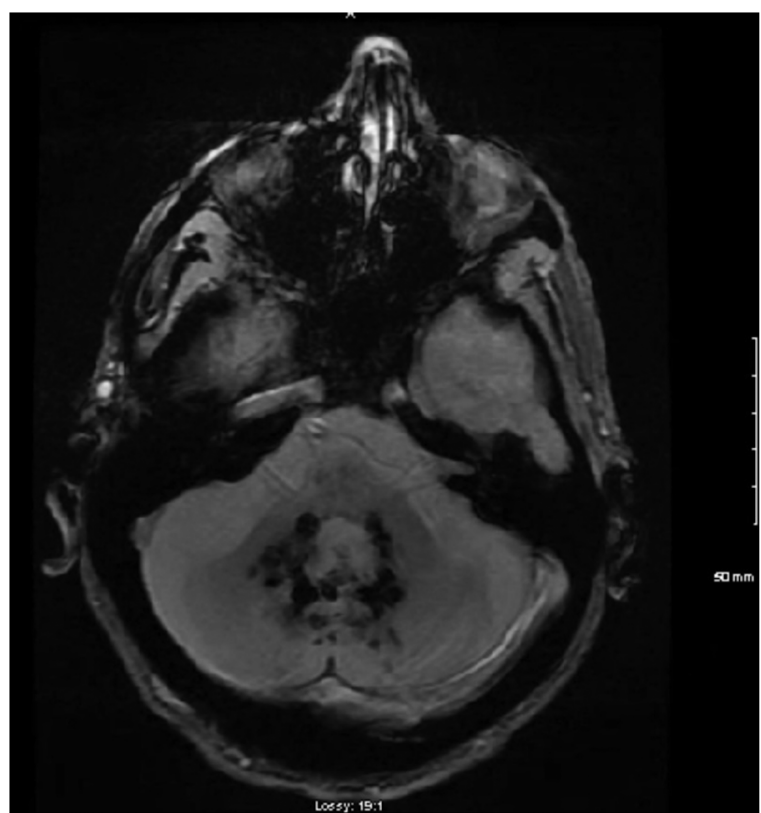

Figure 4 Cerebellar developmental venous anomaly and cerebellar atrophy revealed on MRI, $\mathrm{T}^{*}$ gradient recalled echo weighted.

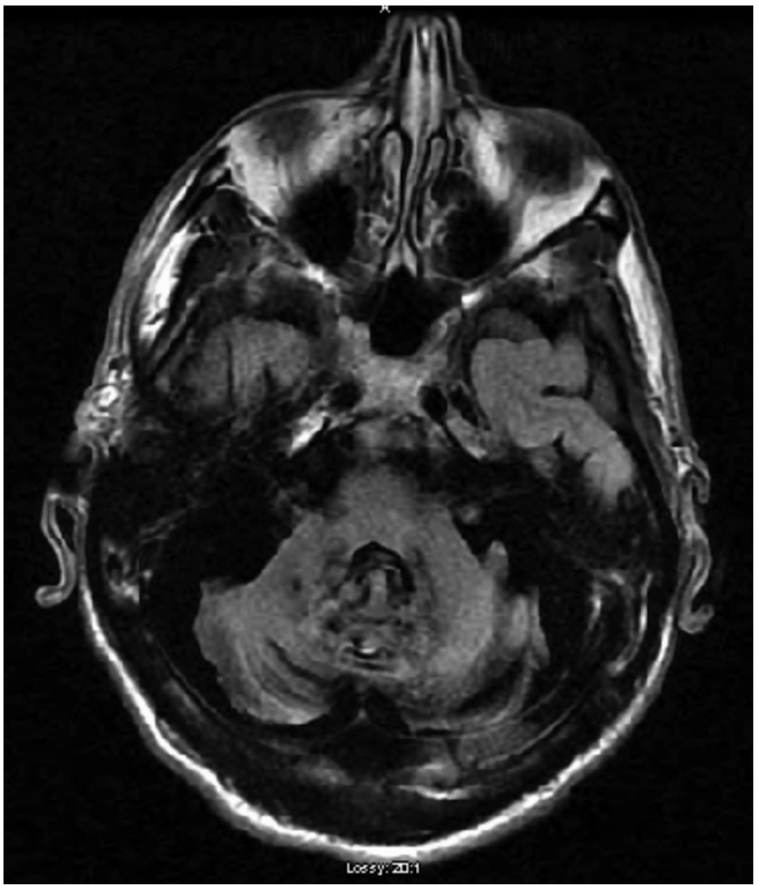

Figure 6 Cerebellar developmental venous anomaly and cerebellar atrophy revealed on MRI, fluid-attenuated inversion recovery weighted.
Figure 5 Cerebellar developmental venous anomaly, cerebellar atrophy and cerebral atrophy revealed on MRI, T1 weighted, sagittal and axial views.

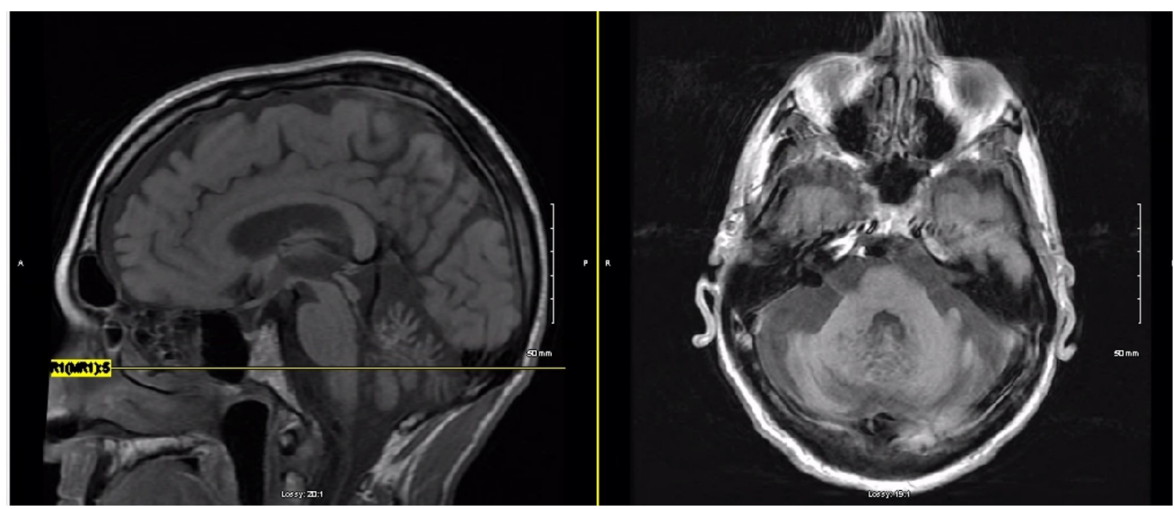

Competing interests None declared.

Patient consent Obtained.

Provenance and peer review Not commissioned; externally peer reviewed.

\section{REFERENCES}

1 Wardle M, Robertson N. Progressive late-onset cerebellar ataxia. Adv Clin Neurosci 2007;7:2.

2 Ruíz DS, Yilmaz H, Gailloud P. Cerebral developmental venous anomalies: current concepts. Ann Neurol 2009:66:271-83.

3 Pereira VM, Geibprasert S, Krings T, et al. Pathomechanisms of symptomatic developmental venous anomalies. Stroke 2008:39:3205-15. 
Copyright 2016 BMJ Publishing Group. All rights reserved. For permission to reuse any of this content visit http://group.bmj.com/group/rights-licensing/permissions.

BMJ Case Report Fellows may re-use this article for personal use and teaching without any further permission.

Become a Fellow of BMJ Case Reports today and you can:

- Submit as many cases as you like

- Enjoy fast sympathetic peer review and rapid publication of accepted articles

- Access all the published articles

- Re-use any of the published material for personal use and teaching without further permission

For information on Institutional Fellowships contact consortiasales@bmjgroup.com

Visit casereports.bmj.com for more articles like this and to become a Fellow 